\title{
SISTEMA DE PRECEDENTES JUDICIAIS NA ORDEM JURÍDICA BRASILEIRA: ANÁLISE DO INSTITUTO COMO MECANISMO DE GESTÃO E ADMINISTRAÇÃO DA JUSTIÇA E DAS REFORMAS EMPREENDIDAS À SUA INTRODUÇÃO.
}

\author{
Giovanni Bonato ${ }^{1}$
}

Aileen Raphysa Sauaia Falcão ${ }^{2}$

\section{RESUMO:}

O artigo propõe-se a analisar o sistema de precedentes judiciais no Direito Brasileiro, centrando-se na relevância da vinculação das decisões dos tribunais e da jurisprudência, notadamente para a gestão e administração da justiça, haja vista a democratização da justiça auferida com o instituto, bem como a proeminência da legitimidade e transparência do Poder Judiciário. Para tanto, torna-se imprescindível traçar um panorama geral sobre os sistemas jurídicos do commom law e civil law, verificando-se, principalmente, a proeminência das decisões vinculantes e, adentrando-se no cenário brasileiro, constatar as manifestações dos precedentes no ordenamento jurídico, inclusive com o novel Código de Processo Civil.

Palavras-chave: Precedentes Judiciais; commom law; civil law; jurisprudência; tribunais, administração da justiça.

\section{SYSTEM OF JUDICIAL PRECEDENTS IN THE BRAZILIAN LEGAL ORDER: ANALYSIS OF THE INSTITUTE AS A MECHANISM FOR MANAGEMENT AND ADMINISTRATION OF JUSTICE AND REFORMS UNDERTAKEN TO ITS INTRODUCTION}

\begin{abstract}
:
The article proposes to analyze the system of judicial precedents in Brazilian Law, focusing on the relevance of the binding of decisions of the courts, especially for the administration of justice, given the democratization of justice obtained with the institute, as well as the prominence of the legitimacy and transparency of the Judiciary. Therefore, it is essential to draw a panorama of the legal systems of common law and civil law, especially the prominence of binding decisions and, within the Brazilian scenario, to verify the manifestations of precedents in the legal system, including with the novel Code of Civil Procedure.
\end{abstract}

Keywords: Judicial Precedents; Commom law; Civil law; jurisprudence; Courts; Administration of justice.

\footnotetext{
${ }^{1}$ Doutor em Direito Processual Civil pela Universidade "La Sapienza" de Roma (Itália). Professor de direito comparado na Universidade de Paris Nanterre (França). Foi Professor Visitante na Faculdade de Direito da Universidade de São Paulo. Atualmente é Professor Visitante na Universidade Federal do Maranhão, Programa de Pós-Graduação em Direito e Instituições do Sistema de Justiça. Advogado.

${ }^{2}$ Mestranda em Direito e Instituições dos Sistemas de Justiça pela Universidade Federal do Maranhão. Especialista em Direito Processual Civil pela Faculdade Damásio de Jesus. Pesquisadora (FAPEMA).
} 


\section{INTRODUÇÃO}

A força que as decisões dos tribunais possuem em determinados ordenamentos jurídicos constitui, em análise superficial, força motriz a ensejar a filiação entre os sistemas do civil law ou do common law. As reiteradas decisões destes tribunais, que vem a caracterizar o que se conhece por jurisprudência geralmente estão associadas à diferença entre estes sistemas jurídicos.

A jurisprudência, dada sua especial relevância ao estudo, será pontuada, tendo em vista que comumente está associada ao termo "precedentes judiciais". Por vezes, identificadas como expressões sinônimas. Contudo, pretende-se demonstrar que a moldura de cada sistema está além dessa preliminar acepção.

De outro turno, o estudo do ordenamento jurídico brasileiro, com a promulgação do novo Código de Processo Civil será objeto de estudo, haja vista que sua sistemática está vinculada à tradição romano-germânica, contudo se observa um movimento doutrinário e legislativo tendente à introdução de elementos do commom law, incluindo o sistema de precedentes obrigatórios, o que faz oportuna a análise neste sentido.

Outrossim, assiste-se um movimento que parece caminhar na contramão da tendência referida acima, qual seja, a dificuldade na vinculação às decisões proferidas no âmbito dos próprios tribunais, respaldada, principalmente, na ênfase à imparcialidade e independência funcional dos magistrados. Acredita-se que, por trás deste discurso, estão manifestos reflexos de uma cultura patrimonialista que exalta a relevância da jurisprudência dos tribunais, mas não a evoca quando profere decisões diferentes em casos pré analisados como similares.

Desta forma, vê-se o cenário atual, com um Poder Judiciário que causa a impressão de insegurança aos jurisdicionados, pois constantemente decide contrariamente ao que estabelece e, por outro lado, o Poder Legislativo juntamente com o Executivo, no fomento à estruturação de um sistema que preze pela certeza e previsibilidade das decisões, notadamente, pelas diversas reformas empreendidas neste sentido, inclusive, com o novel Código de Processo Civil.

Este artigo tem o intuito de apresentar este panorama e fomentar o debate acerca das reformas empreendidas, que demonstram o intuito de modificar a visão que se tem sobre a jurisprudência pátria, tornando-a vinculante, bem como apresentar os obstáculos apresentados para que isto seja concretizado. Ademais, pelo foco do estudo centrar-se nestas transformações 
e repercussões no direito Brasileiro, mostra-se inequívoco apresentar estes debates e o direcionamento dos mesmos, pois constituem objetivos da referida pesquisa. Na perspectiva acima delineada, outrossim, pretende-se perfazer o desenvolvimento da pesquisa

Com o fim de conduzir o estudo sobre as questões apresentadas, será utilizada uma metodologia baseada em pesquisa bibliográfica, principalmente, através de publicações em artigos científicos, livros, periódicos, revistas eletrônicas, legislação, bem como informativos de sites eletrônicos de instituições oficiais, que versem sobre o assunto.

\section{OS SISTEMAS JURÍDICOS DO COMMOM LAW E DO CIVIL LAW}

Comumente faz-se a distinção entre os sistemas jurídicos do Commom Law e do Civil Law de acordo com a primazia que cada um dá a determinada fonte, quais sejam, respectivamente, a jurisprudência e a lei. Tendo em vista saber-se que as diferenças repousam em debates mais profundos, convém destacar determinados pontos que caracterizam cada sistema.

Afeiçoado à tradição anglo-saxônica, o Commom Law primou desde sua origem, que tem marco no período medieval, à salvaguarda das tradições e no respeito ao direito costumeiro. Tal aspecto poderia conduzir, equivocadamente, à conclusão de que em países partidários deste modelo jurídico não existisse um sistema codificado de leis, contudo, principalmente na Inglaterra, referência ao se tratar deste sistema, percebe-se que as leis sempre foram presentes e aplicáveis aos casos concretos, porém a relevância que se dava à jurisprudência era notória. Nesta esteira, destaca René David (DAVID, 2002, p. 415): “O direito dos Estados Unidos é, assim como o direito inglês, um direito essencialmente jurisprudencial”.

Convém, ademais, destacar que a codificação não fora ponto crucial de distinção entre tais sistemas jurídicos, tendo em vista que sempre fora presente em ambos. Ocorre que, apesar da presença e aplicação das leis no Commom Law, abriu-se neste sistema jurídico a possibilidade de interpretação aos juízes, pensando-se em uma sistemática que não poderia ser concebida hermeticamente e, notadamente, fora conduzida de forma diferente à adotada no Civil Law, em que não se dava tal oportunidade ao magistrado quando no exercício da função jurisdicional.

A fácil associação, outrossim, ao Commom Law e ao sistema de precedentes judiciais, como se um instituto tivesse nascido juntamente com o outro, revela-se falaciosa. Acerca deste aspecto, comenta Marinoni: 


\begin{abstract}
(...)qualquer identificação entre o sistema de commom law e a doutrina dos precedentes, qualquer tentativa de explicar a natureza do commom law em termos de stares decisis ${ }^{3}$, certamente será insatisfatória, uma vez que a elaboração de regras e princípios regulando o uso de precedentes e a determinação e aceitação da sua autoridade são relativamente recentes, para não se falar da noção de precedentes vinculantes (binding precedents), que é mais recente ainda. Além de o commom law ter nascido séculos antes de alguém se preocupar com tais questões, ele funcionou muito bem como sistema de direito sem os fundamentos e conceitos próprios da teoria dos precedentes, como, por exemplo, o conceito de ratio decidendi (SIMPSON, A. W. B. The common law and legal theory, in Oxford Essays in Jurisprudence. Oxford: Clarendon Press, 1973, p. 77, apud MARINONI, 2016, p. 17)
\end{abstract}

Tal afirmação dá-se pela constatação de que no medievo "O estudo desse período revela que os juízes ingleses não recorriam às decisões anteriores como fontes do direito" (DUXBURY, 2008, p. 32). De fato, os precedentes judiciais no commom law dão-se retrospectivamente, isto é, firma-se a tese jurídica que constitui a ratio decidendi com base nas decisões anteriores.

Em contraposição ao sistema instituído pela Commom Law, tem-se a tradição romanogermânica que inaugurou o sistema conhecido por Civil Law, que possui referência a partir do período Justiniano, no século VI, em que se tentou compilar todas as ações e situações humanas e sociais, restando ao magistrado a mera aplicação da lei, desnudando este operador do direito de qualquer atividade interpretativa, pois sua função deveria se ater à subsunção da norma ao fato gerador. Deste período decorre, inclusive, a identificação do juiz com a "bouche de la loi".

O surgimento de lacunas, em virtude da impossibilidade de previsão de todas as situações surgidas no seio de uma sociedade ensejaram a flexibilização de um sistema tão rígido e propiciaram uma maior abertura ao magistrado na apreciação dos casos concretos. A existência de cláusulas gerais abertas é um reflexo desta ausência na legislação compilada.

Vale ressaltar que o surgimento de um controle difuso de constitucionalidade no sistema brasileiro, inspirado claramente pelo case norte-americano Marbury versus Madison abriu a possibilidade de um juiz, em caráter incidental, declarar a inconstitucionalidade de lei

\footnotetext{
${ }^{3}$ Em termos precisos, o doutrinador Marinoni (2011, p. 27) explicita o que poderia ser considerado como stare decisis, de forma a considerar que este termo refere-se tanto a vinculação, por meio do precedente, em ordem vertical (ou seja, como representação da necessidade de uma Corte inferior respeitar decisão pretérita de Corte superior), como horizontal (a Corte respeitar decisão anterior proferida no seu interior, ainda que a constituição dos juízes seja alterada). Esta é a posição adotada, entre outros, por Neil Duxbury e Melvin Aron Eisenberg. Em outra senda, há aqueles que optam por distinguir o termo stare decisis de precedent, como Frederik Schauer, para quem, "tecnicamente, a obrigação de uma corte de seguir decisões prévias da mesma corte é dita como sendo stare decisis (...), e o termo mais abrangente precedent é usado para se referir tanto à stare decisis, quanto à obrigação de uma corte inferior de seguir decisões de uma superior.
} 
ou ato normativo. Tal questão propiciou, igualmente, uma fissura neste sistema tão rígido e permitiu maior margem de interpretação aos magistrados.

Acerca do papel do magistrado no âmbito destes dois sistemas, considerando-se sua desenvoltura com o sistema de precedentes judiciais, assevera o doutrinador Marinoni:

\begin{abstract}
Não há dúvida que o papel do juiz do civil law e especialmente o do juiz brasileiro, a quem é deferido o poder-dever de controlar a constitucionalidade da lei no caso concreto, muito se aproxima da função exercida pelo juiz do commom law, especialmente a realizada pelo juiz americano. Acontece que, apesar da aproximação dos papeis dos magistrados de ambos os sistemas, apenas o commom law devota respeito aos precedentes. (MARINONI, 2010, p. 100)
\end{abstract}

Acrescente-se que, no que concerne aos precedentes judiciais no Civil Law, deve-se depreendê-lo, a partir de uma análise prospectiva, isto é, percebe-se que o legislador determina quais decisões serão passíveis de serem observadas como precedentes judiciais que, por sua vez, firmam uma tese jurídica cujos argumentos materiais, denominados de ratio decidenci ${ }^{4}$ irão constituir a fundamentação que vinculará os magistrados.

Feitas tais considerações, passa-se ao cenário brasileiro, que afeiçoado à tradição romano-germânica, desenvolveu-se assentado nas bases do sistema jurídico do Civil Law e, apesar das reformas legislativas inclinadas a sistematizar o ordenamento de forma a tornar vinculante sua jurisprudência, inclusive apontando para a tradição do Commom Law, percebese uma aversão à adoção destes institutos, por vezes respaldados na independência funcional e na imparcialidade dos magistrados.

\title{
3 SISTEMA DE PRECEDENTES JUDICIAIS
}

Conforme destacado acima, costuma-se associar erroneamente a origem do Commom Law com a dos precedentes judiciais. Na verdade, o respeito às decisões foi uma prática construída na Inglaterra e difundida pelas demais colônias como uma forma de manter a coerência do ordenamento jurídico e a igualdade dos sujeitos diante do Judiciário (PUGLIESE, 2016, p. 47). A moderna doutrina dos precedentes inglesa, ou seja, a forma como é vista

\footnotetext{
${ }^{4}$ Luiz Guilherme Marinoni, em sua célebre obra "Precedentes Obrigatórios, dispõe que "não há sinal de acordo , no commom law, acerca de uma definição de ratio decidendi ou mesmo de um método capaz de permitir sua identificação" e refere-se, para sua delimitação e definição ao método de Goodhart, na qual a ratio decidendi é determinada mediante a verificação dos fatos tartados como fundamentais ou materiais pelo juiz. e ao teste de Wambaugh, em que a ratio decidendi seria uma regra geral em cuja ausência o caso seria decidido de outra forma. (MARINONI, 2010, pp. 223- 225) 
atualmente somente assumiu esta moldura no século XVIII, consoante destaca William Pugliese:

Já no início do século XVII os precedentes ganhavam maior importância, mas não foi o suficiente para serem considerados vinculantes pelos juízes e tribunais [...] Somente no século XVIII surgiu a moderna doutrina dos precedentes. Antes disso, as decisões judiciais da Inglaterra não tinham nenhuma força vinculante e eram utilizadas apenas como suporte para os julgamentos (PUGLIESE, 2016, p. 35)

Com o intuito de aprofundar o estudo acerca deste instituto na sistemática brasileira, serão pontuadas questões atinentes a sua natureza, bem como à sua classificação.

De acordo com as lições de Fredie Didier Jr, a origem dos precedentes pode ser classificada em duas:

\begin{abstract}
O conceito lógico-jurídico é aquele construído a priori e de forma universal, porquanto compreende o fenômeno jurídico independentemente do direito positivo, Em vez de ser extraído de determinada realidade normativa, o conceito lógico-jurídico serve ao entendimento de qualquer ordenamento jurídico. São exemplos de conceitos lógicojurídicos no Direito Processual Civil: competência, decisão, tutela jurisdicional, prova, etc. O conceito jurídico-positivo, por sua vez, é erguido a posteriori, a partir de um determinado ordenamento jurídico e, por conseguinte, somente a ele aplicável. Vejam-se alguns exemplos: apelação, recurso especial e prequestionamento. (DIDIER, 2012, pp. 38- 43 apud CRAMER, 2016, pp. 76-77)
\end{abstract}

Convém ressaltar, ademais, que os Precedentes Judiciais e a Jurisprudência possuem diferenças substanciais, principalmente, em termos quantitativos, que segundo o entendimento de Didier, Paula Sarno Braga e Rafael Oliveira estabelece-se (DIDIER, BRAGA e OLIVEIRA, 2015, p. 487, apud CRAMER, 2016, p. 73):

Um precedente, quando reiteradamente aplicado, se transforma em jurisprudência, que, se predominar em tribunal, pode dar ensejo à edição de um enunciado na súmula da jurisprudência deste tribunal. Assim, a súmula é o enunciado normativo da ratio decidendi de uma jurisprudência dominante, que é a reiteração de um precedente.”

A força dos precedentes e a eficácia dos mesmos em um sistema jurídico abre espaço para uma classificação de suma importância para a apreensão do instituto no que tange à indicação do grau ou intensidade com que ele é capaz de influenciar as decisões sucessivas, qual seja, a de considerar os precedentes vinculantes ou persuasivos.

A este respeito, Michelle Taruffo ${ }^{5}$ destaca que a diferença entre ambos com base no sistema jurídico em que estejam inseridos seria pouco confiável, o que facilmente ocorre por

\footnotetext{
${ }^{5}$ Sobre isso, observa-se que a tradicional e corrente distinção entre precedente vinculante, que seria típico dos ordenamentos de common law, e precedente persuasivo, ou de fato, que seria típico dos ordenamentos de civil
} 
associar-se precedentes vinculantes ao sistema do commm law e os persuasivos, por sua vez, ao sistema do civil law.

O que parece notório é que em países de tradição anglo-saxônica os precedentes possuam esta feição vinculante, em virtude de serem dotados de força considerável, refletindose, por exemplo, quando um juiz sucessivo à decisão adota a tese jurídica fixada em um precedente judicial. Ocorre, no entanto, que o sistema não deve conduzir os aplicadores do direito ao engessamento, apesar da intenção em manter a segurança jurídica e a coesão do ordenamento jurídico, o que possibilita aos tribunais fazerem uso de mecanismos capazes de reformular ou afastar um precedente, tais como o overrruling e o distinguinshing, pois a justiça de determinado caso concreto faz-se imperiosa.

Estas hipóteses de afastamento ou superação de uma tese jurídica firmada em determinado precedente judicial, que inegavelmente consagra a estabilidade da ordem jurídica, em contraposição ao discutido engessamento, foram, inclusive, contempladas em enunciado construído no Fórum Permanente de Processualistas Civis, como a seguir se transcreve: "Enunciado n. 306 do FPPC: O precedente vinculante não será seguido quando o juiz ou tribunal distinguir o caso sob julgamento, demonstrando, fundamentadamente, tratar-se de situação particularizada por hipótese fática distinta, a impor solução jurídica diversa.”

A respeito do fenômeno em países de tradição civil law, Michelle Taruffo destaca:

Nos ordenamentos de civil law, o grau de força que vem atribuído ao precedente é, provavelmente, menor do que aquele atribuído ao precedente da common law, mas nada exclui que existam precedentes tão influentes e persuasivos a ponto de serem impostos aos juízes sucessivos. Para eles, no entanto, deixou-se um espaço de possível dissenso, condicionado, porém à indicação das razões adequadas que justifiquem a adoção de uma regra de julgamento diversa (TARUFFO, 2014, p. 8)

A maneira como se opera o precedente, se aplicável no âmbito do mesmo tribunal ou somente nos tribunais inferiores, é relevante igualmente à análise da força dos precedentes e à maneira como tal instituto se delineia em um ordenamento jurídico.

Michele Taruffo, neste sentido, assevera que isto conduz à percepção da "direção" do precedente, que pode ser vertical, que ocorre quando o juiz sucessivo, que deve decidir o caso idêntico ou similar, coloca-se em um grau inferior na hierarquia judicial e isso se dá porque, tradicionalmente, a força do precedente baseia-se na autoridade e na competência do órgão que

law, é pouco confiável. Pelo contrário, parece apropriado falar de força do precedente para indicar o grau ou a intensidade com que ele é capaz de influenciar as decisões sucessivas. (TARUFFO, 2014, p. 7)

Rev. de Política Judiciária, Gestão e Administração da Justiça | e-ISSN: 2525-9822| Maranhão | v. 3 | n. 2 | p. 20 - 35 | Jul/Dez. 
proferiu a decisão; bem como o estudioso o distingue do precedente horizontal, que corresponde à força persuasiva que um precedente pode ter em relação aos órgãos judiciários que pertencem ao mesmo nível daquele que pronunciou a primeira decisão. Assim:

\begin{abstract}
Esta classificação reporta-nos à utilizada no tocante aos efeitos do stare decisis, que expressa a vinculação obrigatória dos precedentes judiciais, igualmente das duas formas supracitadas, ou seja, horizontal e vertical. Acerca destas assertivas e com base na distinção entre stare decisis e precedent, o jurista Marinoni, magistralmente, apresenta um panorama destas terminologias, com suas respectivas pontuações: De regra, o termo stare decisis significa tanto a vinculação, por meio do precedente, em ordem vertical (ou seja, como representação da necessidade de uma Corte inferior respeitar decisão pretérita de Corte superior), como horizontal (a Corte respeitar decisão anterior proferida no seu interior, ainda que a constituição dos juízes seja alterada). Esta é a posição adotada, entre outros, por Neil Duxbury e Melvin Aron Eisenberg. Em outra senda, há aqueles que optam por distinguir o termo stare decisis de precedent, como Frederik Schauer, para quem, "tecnicamente, a obrigação de uma corte de seguir decisões prévias da mesma corte é dita como sendo stare decisis (...), e o termo mais abrangente precedent é usado para se referir tanto à stare decisis, quanto à obrigação de uma corte inferior de seguir decisões de uma superior. (TARUFFO, 2014, p. 9)
\end{abstract}

Findando-se esta breve análise introdutória sobre o sistema de precedentes judiciais, passa-se para o estudo acerca da aplicação no sistema brasileiro, com destaque aos obstáculos encontrados no ordenamento pátrio, bem como nas investidas de introdução do mesmo a partir das reformas legislativas e dos substratos teóricos.

\title{
4 SISTEMA DE PRECEDENTES NO DIREITO BRASILEIRO
}

Constata-se, sem maiores dificuldades, que o ordenamento jurídico brasileiro esteve sempre atrelado ao sistema jurídico do civil law. Refletindo estes parâmetros, percebe-se que somos carreados de códigos colossais e de leis que disciplinam qualquer situação, mesmo as corriqueiras. Ocorre que, torna-se atividade impossível a previsão, por meio da atividade intelectual de um grupo, mesmo que seleto, de juristas, de todos os fatos e atos que venham a importar para o Direito.

Esta constatação não poderia ser distinta na ordem jurídica brasileira, motivo pelo qual muitas reformas na legislação, permitindo maior liberdade ao magistrado, foram engendradas.

Tem-se, a título de exemplo, a reforma promovida pelo Supremo Tribunal Federal com o intuito de alterar seu regimento para a introdução das súmulas de sua jurisprudência, a fim de organizar seu entendimento sobre questões jurídicas controversas, bem como a extensão do 
efeito vinculante em sede de controle concentrado de constitucionalidade, introduzidas pela Emenda Constitucional n ${ }^{\circ}$ 45/2004- conhecida como Reforma do Judiciário-, para os órgãos do Poder Judiciário e a Administração Pública Direta e Indireta, tendo em vista que anteriormente somente se contemplava o Poder Judiciário e o Executivo.

A edição de súmulas vinculantes pelo Supremo Tribunal Federal, neste sentido, acentua a apreensão consistente na construção de uma jurisprudência sumulada, pois a multiplicidade de situações e processos com questões idênticas que poderiam ter desfechos divergentes trariam como consequência grave segurança jurídica e disto decorre a expressa exortação no artigo 103-A, $\S 3^{\circ}$ da Constituição Brasileira, como se verifica abaixo:

Art. 103-A. O Supremo Tribunal Federal poderá, de ofício ou por provocação,
mediante decisão de dois terços dos seus membros, após reiteradas decisões sobre
matéria constitucional, aprovar súmula que, a partir de sua publicação na imprensa
oficial, terá efeito vinculante em relação aos demais órgãos do Poder Judiciário e à
administração pública direta e indireta, nas esferas federal, estadual e municipal, bem
como proceder à sua revisão ou cancelamento, na forma estabelecida em lei. (Incluído
pela Emenda Constitucional no ${ }^{\circ} 45$, de 2004 ) (Vide Lei no 11.417 , de 2006).
$\S 1^{\circ}$ A súmula terá por objetivo a validade, a interpretação e a eficácia de normas
determinadas, acerca das quais haja controvérsia atual entre órgãos judiciários ou
entre esses e a administração pública que acarrete grave insegurança jurídica e
relevante multiplicação de processos sobre questão idêntica. (Inclú́do pela Emenda
Constitucional no $n^{\circ} 45$, de 2004)

$\mathrm{Na}$ seara processual civil, igualmente, se observou um movimento contemplativo da vinculação às decisões dos tribunais, o que pode ser observado no artigo 476 do Código de Processo Civil de 1973, que dispunha sobre a Uniformização da Jurisprudência, um instituto que não possuía natureza recursal e sim de incidente processual, podendo ocorrer no julgamento de certa demanda em um tribunal. Por meio da Uniformização da Jurisprudência, existindo divergência ou mesmo interpretação diferente da que lhe haja dado outra turma, câmara, grupo de câmaras ou câmaras cíveis reunidas, o juiz poderia solicitar o prévio pronunciamento do tribunal acerca de interpretação, a fim de evitar possíveis decisões colidentes. ${ }^{6}$

Nesta esteira, fora introduzido o $\S 1^{\circ}$ ao artigo 555 do Código de Processo Civil de 1973, pela Lei nº 10.352 de 2001, por meio do qual se disciplinou a Assunção de Competência,

\footnotetext{
${ }^{6}$ Art. 476. Compete a qualquer juiz, ao dar o voto na turma, câmara, ou grupo de câmaras, solicitar o pronunciamento prévio do tribunal acerca da interpretação do direito quando:

I - verificar que, a seu respeito, ocorre divergência;

II - no julgamento recorrido a interpretação for diversa da que lhe haja dado.

Parágrafo único. A parte poderá, ao arrazoar o recurso ou em petição avulsa, requerer, fundamentadamente, que o julgamento obedeça ao disposto neste artigo. 
que permitiu ao relator em caso de recurso com relevante questão de direito submeter o julgamento para o órgão colegiado indicado pelo regimento interno. ${ }^{7}$

Estas reformas ensejaram, notadamente, inegável racionalização da prestação jurisdicional e certamente segurança jurídica. Demonstraram o rumo que a ordem jurídica estava sendo delineada, com evidentes traços do sistema jurídico do commom law.

Contudo, apesar dos esforços enveredados nestas inserções, o ordenamento jurídico pátrio sempre demonstrou uma dificuldade em seguir precedentes, o que poderia ser justificado pela tradição romano-germânica a que somos vinculados ou, mais profundamente, pelo contexto cultural em que estamos inseridos.

O doutrinador Luiz Guilherme Marinoni, de forma magistral em obra intitulada "A ética dos Precedentes. Justificativa do novo CPC" aborda este peculiar panorama e aponta que a questão cultural constitui a raiz da obstacularização em se seguir precedentes no contexto brasileiro, o que nos serve como reflexão para a extensão dos aspectos tradicionais, tão ínsitos aos povos e influentes em seu modo de vida.

Segundo Marinoni, houve um momento em que se substituiu a justiça ditada pelo oráculo pela dos homens, o que fomentou a necessidade de fundamentação das decisões proferidas por estes homens e, por conseguinte, a necessidade de uma justificação e previsibilidade tornou-se emergente. Um sistema que surge neste formato reclama uma clareza organizacional, bem como uma abrangência, o que não significa que se pode associá-lo a um sistema jurídico racionalmente formal.

Neste pensamento, este doutrinador relata que o stare decisis torna-se imprescindível para que um sistema que não seja dotado de elevada racionalidade jurídica possa produzir, na prática, maior previsibilidade, tendo em vista que a vinculação às decisões garantirá maior segurança acerca daquelas que sejam proferidas para casos similares. É o que afirma sobre o commom law:

Além disso, o commom law, por não possuir a mesma racionalidade formal do direito
legislado, teria dotado o stare decisis como meio para contrabalançar a sua pouca
racionalidade e previsibilidade. Reafirmar que o commom law não se identifica com

\footnotetext{
${ }^{7}$ Art. 555. No julgamento de apelação ou de agravo, a decisão será tomada, na câmara ou turma, pelo voto de 3 (três) juízes. (Redação dada pela Lei no 10.352, de 2001)

$\S 1$ o Ocorrendo relevante questão de direito, que faça conveniente prevenir ou compor divergência entre câmaras ou turmas do tribunal, poderá o relator propor seja o recurso julgado pelo órgão colegiado que o regimento indicar; reconhecendo o interesse público na assunção de competência, esse órgão colegiado julgará o recurso. (Incluído pela Lei $\mathrm{n}^{\circ} 10.352$, de 2001)
}

Rev. de Política Judiciária, Gestão e Administração da Justiça | e-ISSN: 2525-9822| Maranhão | v. 3 | n. 2 | p. 20 - 35 | Jul/Dez. 
o stare decisis é algo que obviamente não precisa ser evidenciado mediante a obra de Weber. (MARINONI, 2016, p. 44)

No caso brasileiro, observou-se que o patrimonialismo, que influenciou a feitura do Código Civil de 1916 e o Código de Processo Civil de 1973, colheu consequências negativas para nosso sistema jurídico, haja vista que este tipo ideal de sociedade era, de forma sucinta, representado por um senhor que escolhia seus funcionários e delimitava suas respectivas competências com base em critérios puramente subjetivos, em relações pessoais e de confiança. Este traço no seio da sociedade brasileira produziu o "homem cordial" descrito pelo historiador Sérgio Buarque de Holanda, que se mostrava avesso à impessoalidade e a racionalidade formal, tão essencial a um sistema de precedentes que evoca a vinculação às decisões e é desprovido de interesses pessoais que possam influenciar no proferimento de decisões.

Obviamente, estes aspectos culturais impactaram a moldura do Poder Judiciário brasileiro que se converteu para o caráter pessoal das decisões, para a ausência de racionalidade formal e do respeito aos precedentes das Cortes, bem como na dificuldade em se distinguir o público do privado.

Fazendo referência à presença deste "homem cordial" nos tempos hodiernos, constata Marinoni:

(...) ainda tem lugar o "homem cordial", o juiz e o promotor que atuam com base nos velhos motivos que presidiam a família patriarcal, quando tudo girava em torno da pessoalidade. O advogado igualmente é investido dessa figura, tornando-se o "bajulador"que deixa de ser defensor dos direitos para se tornar lobista de interesses privados, para o que são mais efetivas as relações peculiares ao chamado "jeitinho" ou "jeito" do que o conhecimento técnico-jurídico ou capacidade de convencimento do juiz. (MARINONI, 2016, p. 87)

O cenário traçado acima explicita que determinados fatores conduziram à associação, inegavelmente, da incorporação de valores morais ao texto legal. No entanto, a preocupação que deverá ser primordial diz respeito à identidade entre a lei e o Direito, bem como na concepção da jurisdição como expressão da vontade da lei. A necessidade de definir o significado atribuído à lei por meio das Cortes Superiores, de outro turno, fez-se emergente, pois isto implicaria em uma ordem jurídica coerente.

No entanto, o que se percebe na prática forense é o oposto e, frequentemente, veem-se magistrados ancorando suas decisões em princípios, tais como a independência funcional e a imparcialidade. Estas considerações são de especial relevância, pois, como já se afirmara, a ênfase à jurisprudência e a um sistema de precedentes judiciais faz-se necessária para uma ordem jurídica coesa, bem como para a prolação de decisões que reflitam justiça, contudo estes 
devem ser analisados conforme os aspectos inerentes à ordem de cada nação, especialmente sobre a viabilidade ou não de um sistema de precedentes, bem como na identificação de um precedente judicial em um dado ordenamento jurídico.

A ênfase à segurança jurídica, princípio sempre em pauta quando estão em discussão os indicativos acima descritos, é uma preocupação central verificada igualmente por Carlos Aurélio Mota de Souza, ao pontuar:

\begin{abstract}
Ora, a divergência de julgados é elemento extremamente comprometedor dessa segurança e desagregador da harmonia social. A servidão do juiz à lei, a exaltação do caráter impessoal do exercício da jurisdição e a limitação do poder de interpretação judiciária são expressões da necessidade de oferecer segurança. Somos, no entanto, obrigados a conviver com a triste realidade de julgados em sentidos contraditórios e às vezes rigorosamente opostos, o que clama por medidas capazes de homogeneizar os pronunciamentos dos tribunais- até mesmo, ou talvez principalmente, em nome do sagrado valor da isonomia. (SOUZA, p. 198, apud DINAMARCO, 2010, p. 237)
\end{abstract}

Convém ressaltar, ademais, que a legitimidade política dada aos juízes na edição de normas que venham a tornar vinculantes as suas decisões é uma questão que contrasta, inclusive, com o princípio da Separação de Poderes construída por Montesquieu. Como se exemplificou acima, consta na Carta Magna brasileira que as súmulas vinculantes possuem o propósito de amenizar o impacto sobre a insegurança jurídica ao se ater a situações que causem grave insegurança jurídica.

Sobre estas ponderações, destaca Cândido Rangel Dinamarco, em sua ilustre obra "Fundamentos do Processo Civil Moderno":

\begin{abstract}
Não conheço uma crítica sequer que se apoie em eventual questionamento da postura dos órgãos judiciários nessa suas manifestações jurisprudenciais reiteradas que agora poderão ser dotadas de eficácia vinculante. Não é lícito invocar regras abstratas e ortodoxas sobre a separação de Poderes, nem pensar na subsistência radical daquilo que no passado sugerira Montesquieu, para com isso desprezar a realidade do presente e renunciar a soluções práticas de utilidade geral. A separação dos Poderes do Estado obedece sempre à fórmula estabelecida por dado Estado, em dado momento histórico, sem que se possa atribuir-lhe um pormenorizado núcleo universal e permanente. (DINAMARCO, 2010, p. 233)
\end{abstract}

Fixando-se o entendimento de que o hodierno sistema de precedentes judiciais está voltado à uniformização da jurisprudência dos tribunais superiores, de modo a dar ao jurisdicionado maior previsibilidade das demandas judiciais e reduzir o nível de insegurança existente pela possibilidade de decisões díspares em casos cuja semelhança dos fatos materiais indique a aplicação da mesma solução judicial, faz-se oportuno destacar a relevância que o 
Novo Código de Processo Civil, Lei nº 13.105/2015, deu ao tema, pois seu espírito revela clara inspiração estes moldes.

As principais referências aos precedentes judiciais no novel Código de Processo Civil encontram-se nos artigos 926 e 927 do respectivo diploma, apesar de constar poucas vezes a referência à expressão "precedentes". Estes artigos estabelecem normas gerais sobre precedentes, afirmando que os tribunais devem manter a jurisprudência estável, íntegra e coerente, bem como define quais precedentes possuem força vinculante, além de estabelecer algumas regras sobre aplicação, modificação e publicidade do precedente.

Esta detecção ocorre, sobretudo, para fins de identificação de um precedente judicial e se este é caracterizado como vinculante ou persuasivo em uma determinada ordem jurídica. Acerca da perspectiva e identificação de um precedente, sinaliza Ronaldo Cramer que existe uma diferença peculiar em países filiados ao sistema do commom law, pois o julgado não nasceria com a característica de ser um precedente e, de outro turno, tem-se que nos países de civil law, em especial o Brasil, constata-se um precedente com a característica de vinculante se isto estiver determinado previamente por lei. Assim, ele discorre:

\footnotetext{
No Direito brasileiro, os precedentes vinculantes encontram-se previstos em lei, e, por esse motivo, já se conhecem previamente as decisões que ostentam esse status. Logo, o julgado, quando precedente vinculante, já nasce com essa condição, e o tribunal, no momento em que o produz, sabe que seu pronunciamento constituirá uma diretriz decisória que subordinará julgamentos futuros.

Assim ocorre com todos os precedentes vinculantes do art. 927 do NCPC, a saber: as decisões definitivas de mérito nas ações de controle concentrado de constitucionalidade, as súmulas vinculantes, as decisões nos incidentes de assunção de competência e de julgamento de casos repetitivos, as súmulas do STF e do STJ, e as decisões dos órgãos de cúpula dos tribunais. Todos esses provimentos judiciais já são proferidos com o status de precedentes vinculantes. (CRAMER, 2016. p. 79)
}

Contudo, e a fim de tornar o discurso mais democrático, destaca-se que existem posições que adotam o oposto, qual seja, a inviabilidade de se conceber um sistema de precedentes judiciais brasileiro de caráter vinculante/obrigatório nos artigos referidos acima. Esta é a posição defendida por Teresa Wambier, Maria Lúcia Lins Conceição, Leonardo Ferres da Silva Ribeiro e Rogério Licastro Torres de Mello, nos seguintes termos e conclusões:

Há a obrigatoriedade que poderíamos chamar de forte- que se não respeitada cabe, para correção da decisão que a desrespeitou, um remédio especificamente concebido com esta finalidade. Infelizmente, no Brasil, parece ser este o único caso em que se considera realmente haver obrigatoriedade. Um bom exemplo é o cabimento da reclamação contra decisão que desrespeita acordão do STJ ou do STF, em julgamento de recursos repetitivos. (CRAMER, 2016. p. 184) 
Com base nestas pontuações, deve-se concluir que o novo Código de Processo civil produz clara exortação à vinculação as decisões proferidas pelos órgãos colegiados indicados nos artigos supracitados. Para fins didáticos, transcreve-se o referido artigo 926.

Art. 926. Os tribunais devem uniformizar sua jurisprudência e mantê-la estável, íntegra e coerente.

$\S 1$ o Na forma estabelecida e segundo os pressupostos fixados no regimento interno, os tribunais editarão enunciados de súmula correspondentes a sua jurisprudência dominante.

$\S 20$ Ao editar enunciados de súmula, os tribunais devem ater-se às circunstâncias fáticas dos precedentes que motivaram sua criação.

Além da questão já ventilada acerca da necessidade em se manter a jurisprudência estável e coerente, este artigo alude à imprescindível atenção às circunstâncias fáticas dos precedentes em seu parágrafo $2^{\circ}$. Isto fomenta o interesse em se perquirir os fundamentos que motivaram um dado precedente, pois este constitui a ratio decidendi do precedente e será a parte vinculante da decisão. Em consonância a este pensamento, tem-se o Enunciado ${ }^{\circ} 166$ do Fórum Permanente de Processualistas Civis, que em seus termos afiança: "A aplicação dos enunciados das súmulas deve ser realizada a partir dos precedentes que os formaram e dos que os aplicaram posteriormente".

O artigo 927 do novo Código de Processo Civil, por sua vez, enuncia a observância a ser feita pelos juízes e tribunais em suas decisões, no tocante a segurança jurídica, isonomia, proteção da confiança, ou seja, princípios basilares à finalidade do sistema de precedentes judiciais, como se observa abaixo:

Art. 927. Os juízes e os tribunais observarão:

§ 3o Na hipótese de alteração de jurisprudência dominante do Supremo Tribunal Federal e dos tribunais superiores ou daquela oriunda de julgamento de casos repetitivos, pode haver modulação dos efeitos da alteração no interesse social e no da segurança jurídica.

§ 4o A modificação de enunciado de súmula, de jurisprudência pacificada ou de tese adotada em julgamento de casos repetitivos observará a necessidade de fundamentação adequada e específica, considerando os princípios da segurança jurídica, da proteção da confiança e da isonomia.

Ressalte-se que, conforme fora destacado, as reformas empreendidas tem por fito garantir maior segurança jurídica ao jurisdicionado e, por conseguinte, tornar a ordem jurídica coesa. Resta observar se as exortações implementadas serão incorporadas ao espírito brasileiro, tão acostumado na prática forense a desrespeitar seus próprios entendimentos e a descuidar-se dos impactos institucionais e sociais de suas decisões. 


\section{CONSIDERAÇÕES FINAIS}

O sistema de Precedentes Judiciais, de eficácia vinculante ou persuasiva, apresenta-se como instituto essencial à fomentação de um ordenamento jurídico coeso e com anseios de promover a justiça das decisões, e clara consagração dos princípios da isonomia e da segurança jurídica.

Percebeu-se, ademais, que as nações, guiadas por seu processo de construção social, cultural e política estiveram afeiçoadas a tradições que conduziram a construção de seus ordenamentos e, apesar de suas particularidades, aproximavam-se dos dois principais sistemas jurídicos existentes, o commom law e o civil law.

O caso brasileiro, consoante se verificou, esteve atrelado à tradição romano-germânica e apresentou traços de um patrimonialismo construído em solo brasileiro, porém com traços da herança colonial portuguesa, que aproximou o público e o privado, na medida em que não se sabia onde cada espaço terminava ou iniciava, bem como inegavelmente recebeu influências, principalmente no ramo processualista civil, de institutos europeus, principalmente italianos e franceses.

Constatou-se a dificuldade, muitas vezes albergada em princípios que garantem ampla liberdade ao magistrado, em seguir precedentes judiciais na ordem jurídica brasileira, apesar dos esforços no sentido de introduzir este instituto, em favor da coesão e estabilidade, consagrando a função pública da jurisdição e servindo ao jurisdicionado, principal prejudicado e destinatário das inconstâncias judiciais.

As reformas legislativas, sobretudo com a promulgação novo Código de Processo Civil, ressaltam esta emergente necessidade. Espera-se, por conseguinte, que este espírito reformado esteja presente na prática forense, com a vinculação das decisões dos tribunais, de forma a sentir que fazemos parte de uma ordem jurídica coerente e harmoniosa.

\section{REFERÊNCIAS}

CRAMER, Ronaldo. Precedentes Judiciais: teoria e dinâmica, $1^{\text {a }}$ edição- Rio de Janeiro: Forense, 2016. Rev. de Política Judiciária, Gestão e Administração da Justiça | e-ISSN: 2525-9822| Maranhão | v. 3 | n. 2 | p. 20 - 35 | Jul/Dez. 
DAVID, René. Os Grandes Sistemas do Direito Contemporâneo. 3. ed. São Paulo: Martis Fones, 2002.

DUXBURY, Neil. The nature and authority of precedent. Cambridge: Harvard University Press, 2008.

DINAMARCO, Cândido Rangel. Fundamentos do processo civil moderno. 6.ed. São Paulo: Malheiros, 2010, v. I.

MARINONI, Luiz Guilherme. A ética dos precedentes: justificativa no novo CPC, $2^{\mathrm{a}} \mathrm{Ed}$. Ver., atual e ampl. São Paulo: Editora Revista dos Tribunais, 2016.

MARINONI, Luiz Guilherme. Aproximação crítica entre as jurisdições de civil law e de common law e a necessidade de respeito aos precedentes no Brasil. Revista da Faculdade de Direito - UFPR, Curitiba, n.49, p.11-58, 2009.

MARINONI, Luiz Guilherme. Precedentes obrigatórios. $2^{\circ}$ ed. rev. e atual. São Paulo: Revista dos Tribunais, 2011.

PUGLIESE, William. Precedentes e a civil law brasileira: interpretação e aplicação do novo código de processo civil, São Paulo: Editora Revista dos Tribunais, 2016.

TARUFFO, Michele. Precedente e jurisprudência. Trad. Chiara de Teffé. Civilistica.com. Rio de Janeiro, a. 3, n. 2, jul.-dez./2014. Disponível em: <http://civilistica.com/precedenteejurisprudencia/>. 06/ junho/2017.

http://www.planalto.gov.br/ccivil_03/_ato2015-2018/2015/lei/113105.html. Acesso em 07/ junho/2017.

http://www.planalto.gov.br/ccivil_03/constituicao/constituicao.html. Acesso em 07/ junho/2017. 